\title{
Influence of processing parameters on quality factors of one-shot hybrid structures made by RTM
}

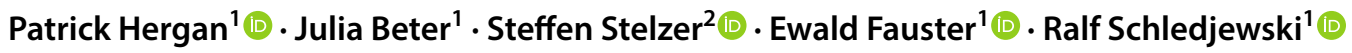

Received: 15 November 2017 / Accepted: 9 February 2018 / Published online: 21 February 2018

(c) The Author(s) 2018. This article is an open access publication

\begin{abstract}
This paper is dealing with the influence of processing parameters for manufacturing of steel-carbon-fiber-reinforced-plastic (CFRP) hybrid plates by using the one-shot-hybrid resin-transfer-moulding (OSH-RTM) process. A design of experiments study was carried out. The quality of the manufactured parts was quantified by the bending modulus, the apparent interlaminar shear strength (ILSS), the maximum deflection and the density of the CFRP. The following changeable processing parameters were chosen: mould temperature, resin temperature, change in mass flow and maximum injection pressure. It is shown that the mould temperature and the change in mass flow show significant impact on the flexural modulus, density and maximum deflection of the plate while there is no significant impact on the apparent ILSS. Furthermore, the interaction between the mould temperature and resin temperature is having an influence on the flexural modulus and density.
\end{abstract}

Keywords CFRP-metal hybrid composites · Temperature induced deflection $\cdot$ Processing parameters $\cdot$ Resin transfer moulding $\cdot$ Processing of composite materials

\section{Introduction}

Hybrid materials and structures have become a new and promising branch in the world of material and part design. Compared to the base materials, such hybrid material combinations show superior properties. They are closing the gap between commonly used materials like metals and upcoming materials like fiber-reinforced-plastics (FRP) [1]. This enables engineers to design parts which require particularly high stiffness, low weight and high impact resistance. Especially the impact resistance is increased due to the ductility of the metal component. Composites themselves are already hybrid materials consisting of reinforcing fibers and a matrix system fixing them together and forming a rigid body. This means that the manufacturing step of a composite structure is not only building the final component but also the

Patrick Hergan

patrick.hergan@unileoben.ac.at

1 Processing of Composites Group, Department Polymer Engineering and Science, Montanuniversität Leoben, Otto Glöckel-Strasse 2, 8700 Leoben, Austria

2 Materials Science and Testing of Polymers, Department Polymer Engineering and Science, Montanuniversität Leoben, Otto Glöckel-Strasse 2, 8700 Leoben, Austria composite material itself. One can conclude that this step is not only defining the geometrical dimensions of the component but also the mechanical properties of it. This gets even more important if a hybrid component is made. In this case the matrix system of the carbon-fiber-reinforced-plastic (CFRP) is also building the interface towards, for instance, the metal component. In this work, a hybrid material consisting of CFRP and steel was considered. The manufacturing step was made by using a one-shot-hybrid resin-transfermoulding (OSH-RTM) process. In difference to the state of the art production method this processing type is saving the time-consuming gluing step where the metal component is joined together with the CFRP after producing each component individually. The OSH-RTM process, which is shown in Fig. 1, is consisting of six major steps. At first the carbon fabric is cut, followed by a layup and preforming step. Further the preform and the metal part are placed in the mould and the mould is closed. This is followed by the resin injection were the matrix system is injected at a defined mass flow rate and a resulting fluid pressure. After the filling is done the resin is cured under increased temperature to reduce the curing time. As a last step, the mould can be opened and the final hybrid part can be demoulded.

The RTM process was already used in the 1990s to produce CFRP components for upper class and sport cars as 


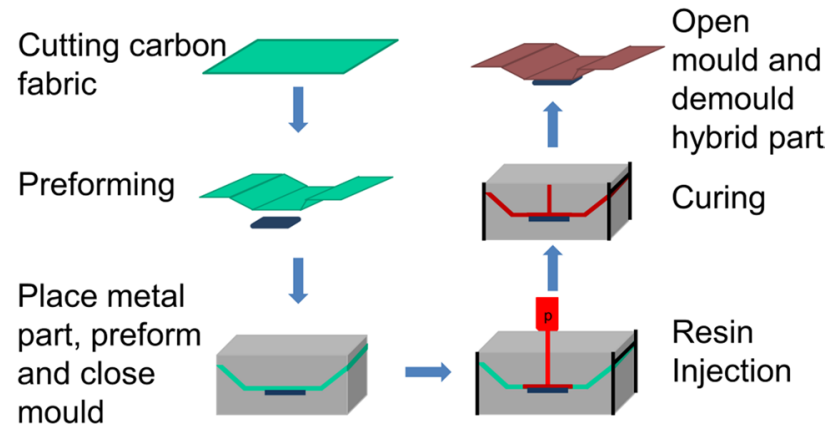

Fig. 1 Schematics of the one-shot hybrid RTM process

well as for aeronautic parts [2-4]. Chassis of high-volume series cars are still mainly made of metals. In order to build chassis consisting of CFRP and steel or aluminum, connection points between the different materials are needed $[5,6]$. In order to avoid damaging the CFRP structure by drilling holes, joints based on screws and rivets should be eliminated and an adhesive should be used instead [7, 8]. There are different methods available to enhance bonding quality such as corona treatment, sand blasting or etching [9-11]. While the influence of the surface treatment and interface layer onto the mechanical properties of such hybrids was studied by Wang et al. $[12,13]$, the impact of variable processing parameters has not been considered yet. As described above, the OSH-RTM process is using the matrix system as an adhesive $[12,14,15]$. This saves the production step of gluing but also hides some challenges. Due to the different thermal expansion coefficients of the CFRP and the steel plate as well as curing at elevated temperature, thermally induced stresses are developing while cooling the part to ambient temperature $[16,17]$. These stresses can lead to deformation or even debonding of the constituents [18]. It is known that preform impregnation strongly impacts the void formation and therefore the mechanical properties of the composite part [19-21]. The aim of this work is to study the influence of processing parameters on hybrid CFRP-steel-components in order to establish optimum processing conditions in order to minimize part deformation and to enhance the mechanical properties of the hybrid part. Taking these objectives into account, a statistical analysis of quality parameters was carried out while varying the changeable processing parameters of the RTM process.

\section{Experimental work}

In order to investigate the influence of the processing parameters of the OSH-RTM process on the hybrid part quality the following parameters were chosen: Mould temperature, resin preheating temperature, mass flow change and maximum
Table 1 Defined processing parameters for the OSH-RTM process with high and low level

\begin{tabular}{llllrr}
\hline Parameter & Abbreviation & Symbol & Unit & Low & High \\
\hline Mould temperature & TMould & A & ${ }^{\circ} \mathrm{C}$ & 100 & 120 \\
Resin temperature & TResin & B & ${ }^{\circ} \mathrm{C}$ & 65 & 75 \\
Mass flow change & mf. ch. & $\mathrm{C}$ & $\mathrm{g} / \mathrm{min}^{2}$ & 60 & 120 \\
$\begin{array}{l}\text { Max. injection pres- } \\
\text { sure }\end{array}$ & max. inj. p. & $\mathrm{D}$ & bar & 10 & 20 \\
\hline
\end{tabular}

injection pressure. For the design of experiments (DoE) study presented in this work, each of these parameters was varied between two distinct levels as listed in Table 1.

To quantify the quality of the product flexural modulus, apparent interlaminar shear strength (ILSS), maximum deflection and density of the CFRP were characterized. The density was used as a quality parameter as it is strongly affected by the void content in the CFRP.

\subsection{Material}

Table 2 is showing the used materials for the manufacturing of the hybrid steel-CFRP plates. In total 48 plates with dimensions of $270 \times 270 \times 4 \mathrm{~mm}$ were produced.

The steel plate was sandblasted on the side which is in contact with the fiber fabric. This is enlarging the surface area and is also giving the surface valleys which are facilitating a better bonding [22]. A thin glass fiber fabric was used to prevent the steel from contact corrosion which occurs when carbon fibers are in contact with base metals [23, 24]. Figure 2 shows the stack sequence of the hybrid plate while the symbols a, b, c and d are referring to the materials shown in Table 2 while $2 \mathrm{~mm}$ of the plates were made of a steel plate and the other $2 \mathrm{~mm}$ were made from the composite.

The composite part of the hybrid was designed as a symmetric laminate. Nevertheless, the whole plate is unsymmetrical as the metal plate is rigidly joined towards the composite.

\subsection{Experimental setup}

For the DoE study, a fractional factorial design was chosen to reduce the amount of experiments. This led to eight different settings for the chosen process parameters which are shown in Table 3. All parameters were set to a high and low level. The resin temperature was varied between 65 and $75{ }^{\circ} \mathrm{C}$. At a too low temperature the resin is getting a high viscosity and is no longer processable with an automated injection unit. The high temperature point was set at a level were the heating unit of the injection unit can still achieve a uniform heat distribution in the resin 
Table 2 Used materials for the production of the hybrid steelCFRP-plates

\begin{tabular}{lllll}
\hline Material & Specification & Supplier & Areal Weight & Symbol \\
\hline Metal & Steel 1.0548 HC340LA & TK & - & a \\
Carbon fibres & Style 423-1, 6K & ECC & $253\left(\mathrm{~g} / \mathrm{m}^{2}\right)$ & $\mathrm{b}$ \\
Carbon fibres & 650SA4, 12K HS & Chomarat & $670\left(\mathrm{~g} / \mathrm{m}^{2}\right)$ & $\mathrm{c}$ \\
Glass fibres & microlith ST 3022 & Johns Manville Corp & $27\left(\mathrm{~g} / \mathrm{m}^{2}\right)$ & $\mathrm{d}$ \\
Resin & Epinal IR 77.55-A1 & bto-epoxy & - & - \\
Curing agent & Epinal IH 77.55-B1 & bto-epoxy & - & - \\
\hline
\end{tabular}

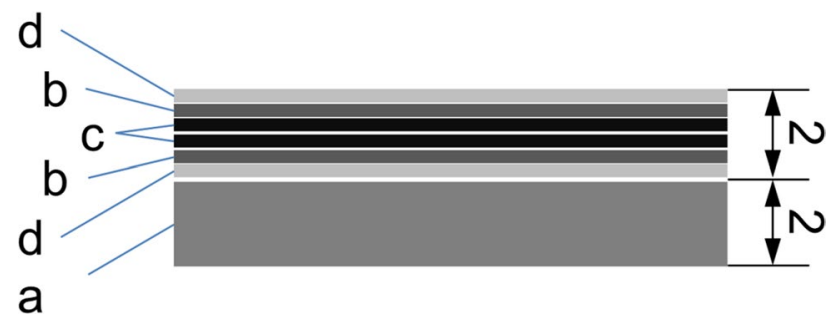

Fig. 2 Layup of the hybrid plate with a steel HC340LA, b Style 423$1,6 \mathrm{~K}$ carbon fabric, $\mathbf{c} 650 \mathrm{SA} 4,12 \mathrm{~K}$ carbon fabric and $\mathbf{d}$ microlith ST 3022 glass fabric

Table 3 Settings for the fractional factorial design for the DoE study

\begin{tabular}{lllll}
\hline Set nr. & $\begin{array}{l}\text { Resin } \\
\text { temp. }\left({ }^{\circ} \mathrm{C}\right)\end{array}$ & $\begin{array}{l}\text { Mould } \\
\text { temp. }\left({ }^{\circ} \mathrm{C}\right)\end{array}$ & $\begin{array}{l}\text { Mass flow } \\
\text { change }\left(\mathrm{g} / \mathrm{min}^{2}\right)\end{array}$ & $\begin{array}{l}\text { Max. inj. } \\
\text { pressure } \\
\text { (bar) }\end{array}$ \\
\hline$\# 1$ & 65 & 100 & 60 & 10 \\
$\# 2$ & 75 & 120 & 60 & 10 \\
$\# 3$ & 65 & 120 & 60 & 20 \\
$\# 4$ & 75 & 100 & 60 & 20 \\
$\# 5$ & 65 & 120 & 120 & 10 \\
$\# 6$ & 75 & 100 & 120 & 10 \\
$\# 7$ & 65 & 100 & 120 & 20 \\
$\# 8$ & 75 & 120 & 120 & 20 \\
\hline
\end{tabular}

pot. The mould temperature was set to 100 and $120{ }^{\circ} \mathrm{C}$, respectively. The proposed curing cycle for the used resin system is $25 \mathrm{~min}$ at $100{ }^{\circ} \mathrm{C}$. To achieve a higher glass transition temperature, $120^{\circ} \mathrm{C}$ was chosen as the second mould temperature level. The curing time was kept constant at $25 \mathrm{~min}$ for all experiments. At all settings, the initial mass flow of the injection was chosen to be $150 \mathrm{~g} /$ min. Depending on the parameter set the mass flow was raised linearly by 60 or $120 \mathrm{~g} / \mathrm{min}^{2}$ during the injection. At the maximum injection pressure, the injection unit is controlling the mass flow towards a value where the pressure stays constant. The high value was set to 20 bar while the low value was set to 10 bar. All the settings were repeated six times and randomized.

\subsection{Plate production}

All the experiments were carried out in a steel mould with cavity dimensions of $270 \times 270 \times 4 \mathrm{~mm}$, which is heated by a water-based heating system of type Thermo-5 HB$180 \mathrm{Z} 2$ by HB-Therm. Prior to the manufacturing of the hybrid plates the ACMOScoat 82-1181-71 release agent from ACMOS Chemie KG was applied. The mould was mounted on a Langzauner LZT-OK-80-SO press which was applying a load of $300 \mathrm{kN}$ throughout the experiment. The resin system was heated and injected with a Tartler Nodopur VS-2K injection unit. After 25 min of curing the hybrid plate was demoulded and cooled down to ambient temperature $\left(23^{\circ} \mathrm{C}\right)$ by free convection.

\subsection{Test setup}

The plates were measured using a laser triangulation sensor scanning the surface with a $60 \times 60 \mathrm{~mm}$ grid while taking measurements every $1 \mathrm{~mm}$. A margin of $15 \mathrm{~mm}$ from the sides was skipped from measurement. Afterwards the specimens for the two three-point bending tests were cut out by using a waterjet cutting device. Figure 3 is showing the dimensions and positions of the interlaminar shear strength (ILSS) (based on the ISO 14130:1997 standard) and flexural modulus specimens (based on the ISO 14125:2011 standard) in the hybrid plate.

The ILSS tests were carried out with a Zwick Z250 universal testing machine. The measurements of the flexural modulus were made with a Zwick Z010. In both cases, a $10 \mathrm{kN}$ load cell was used and the steel side was turned upwards. The span of the supports for the apparent ILSS measurement was $20 \mathrm{~mm}$ while the span for the $E_{\mathrm{f}}$ measurement was $160 \mathrm{~mm}$.

The ILSS specimen were used to additionally measure the density of the CFRP. After running the ILSS test, the CFRP was removed completely from the steel. The density of the CFRP was then measured with a Mettler Toledo Density Kit and scaled using the differential weight procedure with a water bath. 


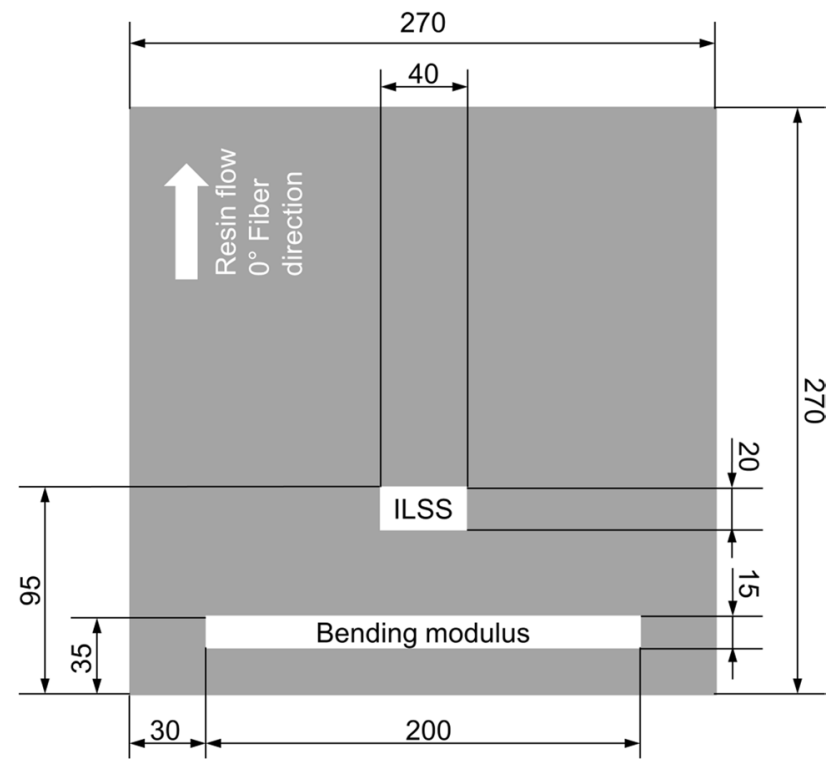

Fig. 3 Position and dimensions of the ILSS and flexural modulus specimens in the hybrid plate

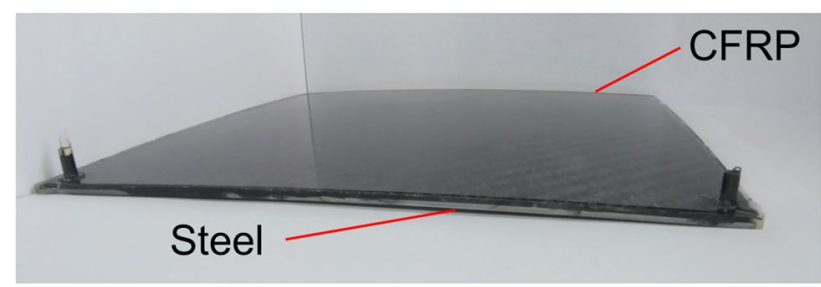

Fig. 4 Picture of a hybrid steel-CFRP plate manufactured with Set \#1

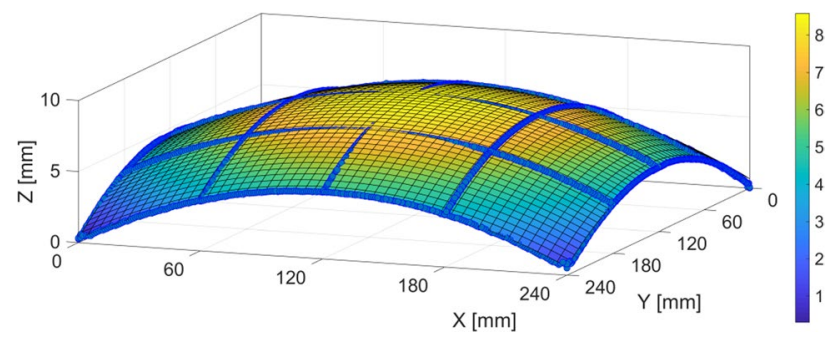

Fig. 5 Measurement of the deflection of the hybrid plate manufactured with Set \#1

\section{Results}

A total of 48 plates were produced and for each plate the flexural modulus, ILSS, deformation and CFRP density was determined. Figure 4 is showing a hybrid plate from Set \#1 configuration listed in Table 3.

Figure 5 is showing the surface scan corresponding to the plate depicted in Fig. 4. The blue lines show the

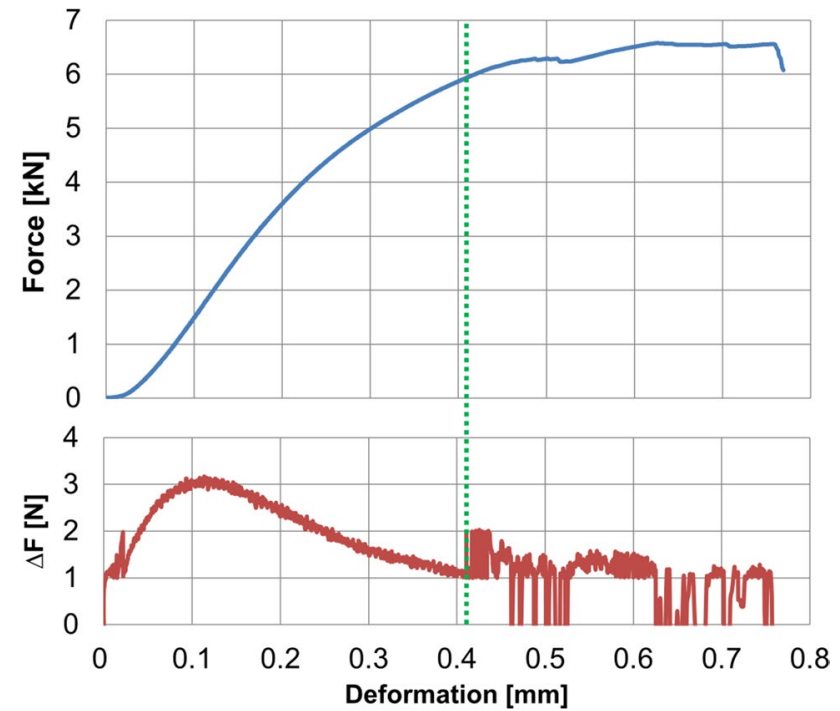

Fig. 6 Load versus deformation and change of load versus deformation plot for an ILSS measurement for Set \#1

measurements points while the colored area is showing the interpolated surface of the plate which is modeled by a second order surface equation. As maximum deflection, the point with the highest $\mathrm{z}$ value was chosen.

For the ILSS measurements the point of the first damage at the specimen was taken. As an example, the measurement of an ILSS test for Set \#1 is shown in Fig. 6 One can see that the change of force is showing a discontinuous behavior shortly after $0.4 \mathrm{~mm}$ deformation. The load $\mathrm{F}$, where this behavior was observed is indicated with a dotted vertical line and was taken as basis for the calculation of the apparent ILSS $\tau$ as mentioned in Eq. (1):

$\tau=\frac{3}{4} \times \frac{F}{b \times h}$,

with $\tau$ representing the apparent ILSS, $\mathrm{b}$ and $\mathrm{h}$ denoting the cross-sectional width and height of the specimen, respectively.

The flexural modulus $\mathrm{E}_{\mathrm{f}}$ was calculated based on the ISO 14125:2011 standard according to Eq. (2) where $E_{f}$ is the flexural modulus, $\mathrm{L}$ is the unsupported length, $\mathrm{b}$ and $\mathrm{h}$ the cross-sectional width and height of the specimen, respectively and $\Delta \mathrm{F} / \Delta \mathrm{s}$ is the gradient of force $\mathrm{F}$ and deformation $\mathrm{s}$ between 0.05 and $0.25 \%$ strain.

$E_{f}=\frac{L^{3}}{4 b h^{3}} \times \frac{\Delta F}{\Delta s}$.

\subsection{Statistical analysis}

The intension of the DoE study is to analyze the influence of processing parameters on the quality of the produced 


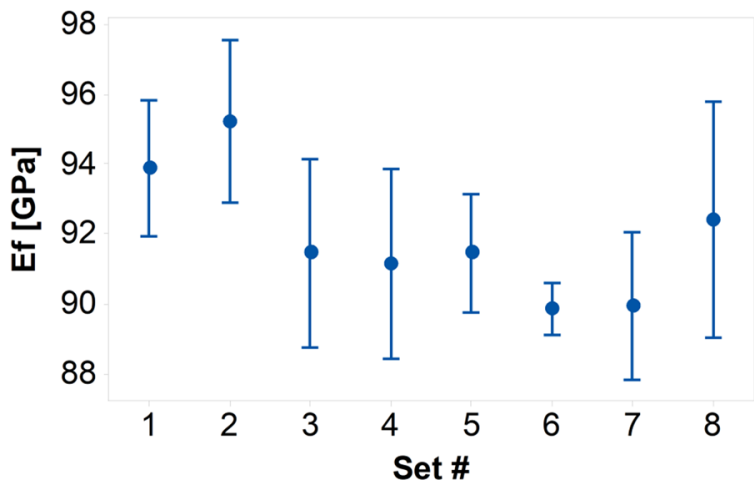

Fig. 7 Mean of flexural modulus $E_{\mathrm{f}}$ for each setting of the DoE study including $90 \%$ confidence interval

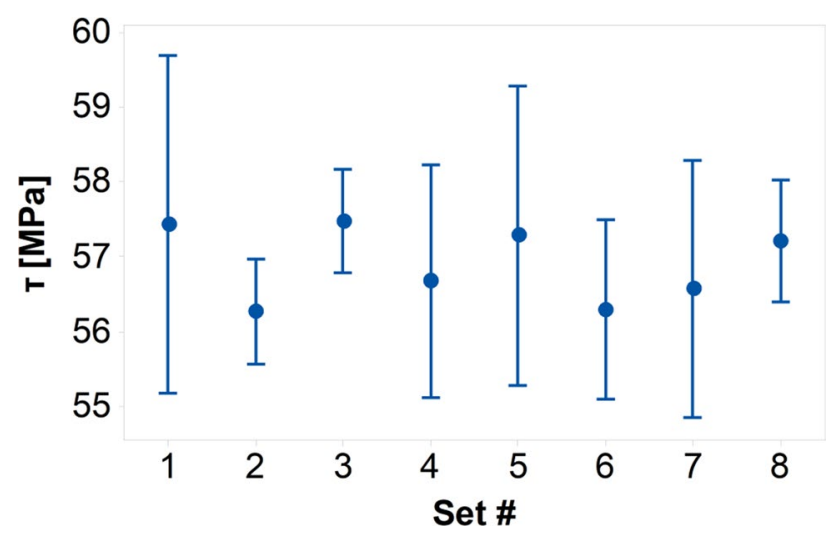

Fig. 8 Mean of apparent ILSS $\tau$ for each setting of the DoE study including $90 \%$ confidence interval

hybrid steel CFRP part. The study also enables to find interactions between the processing parameters. Therefore, the interactions of the first order were investigated too. To find outliers a Grubbs test and a Dixon's Q ratio test both with a significance level of 0.25 were carried out, while a maximum of one of the six points was not taken into account for the statistical analysis for each setting [25, 26].

Figure 7 is displaying the results for the flexural modulus $E_{f}$. There is a difference at the standard deviations as well as a change of the mean value for the different settings. Set \#6 is showing the lowest variation while the result of Set \#8 is showing the highest. The highest modulus of $95.22 \mathrm{GPa}$ was measured at Set \#2 while Set \#6 is showing the lowest modulus of $89.84 \mathrm{GPa}$.

The ILSS measurements which are shown in Fig. 8 are showing a big standard deviation for most of the measurements. This phenomenon is often observed at this kind of measurement. One can see that the standard deviation at Set \#1 is the highest while Set \#3 is showing the lowest. The highest apparent ILSS of 57.47 MPa was measured

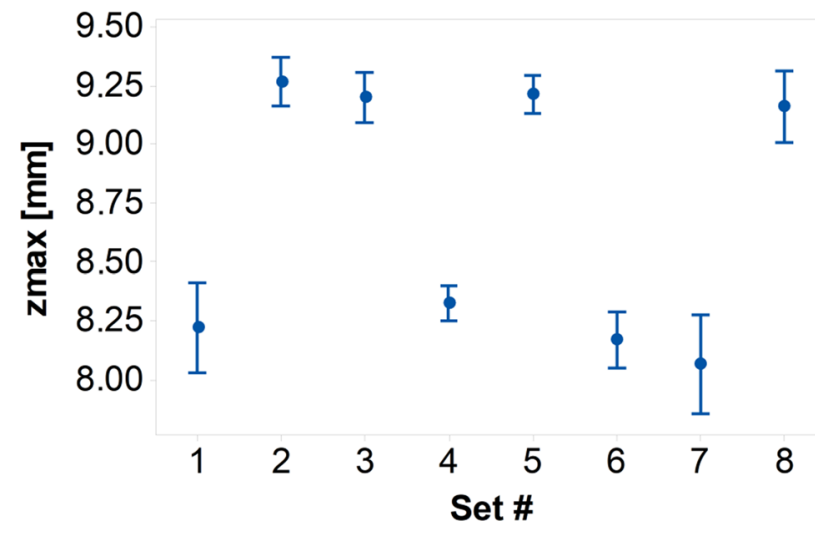

Fig. 9 Mean of maximum deflection $\mathrm{z}_{\max }$ for each setting of the DoE study including $90 \%$ confidence interval

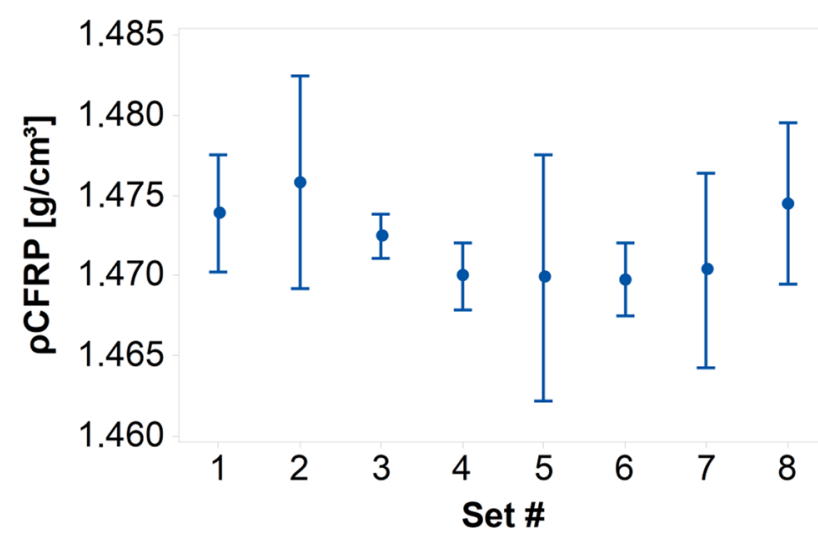

Fig. 10 Mean of CFRP density $\rho_{\text {CFRP }}$ for each setting of the DoE study including $90 \%$ confidence interval

at Set \#3 while the lowest with $56.27 \mathrm{MPa}$ was observed at Set \#2.

A clear difference of the maximum deflection for the different settings is visible at Fig. 9. All standard deviations are quite low, Set \#4 is showing the lowest and Set \#7 is showing the highest. The lowest maximum deflection of $8.06 \mathrm{~mm}$ can be observed at Set \#7 while Set \#2 is showing the highest value of $9.27 \mathrm{~mm}$.

Figure 10 shows the results for the CFRP density $\rho_{\mathrm{CFRP}}$. A difference of the standard deviations can be observed. While Set \#3, \#4 and \#6 are showing rather low variations, Set \#2, \#5 and \#7 are showing much higher standard deviations. The highest density of $1.476 \mathrm{~g} / \mathrm{cm}^{3}$ was measured at Set \#2 while Set \#6 is showing the lowest density of $1.470 \mathrm{~g} / \mathrm{cm}^{3}$.

Analyzing the data shown in Figs. 7, 8, 9 and 10, effect plots and Pareto charts can be created [27]. The Pareto chart enables one to decide if the effect is significant, while the effect plots show in which direction the observed quality parameter is affected, when a processing parameter is 
changed. Due to the standardization of the effects in the Pareto charts the impact of each processing parameter on a quality parameter can be seen. All bars which are longer than the red striped line, which is indicating the $(1-\alpha / 2)$ quantile of a t-distribution with degrees of freedom equal to the degrees of freedom for the error term, are indicating a significant effect with a probability of $90 \%$ (at a standardized effect of 1.68) [28]. The models for the Pareto charts for $E_{f}$ and $z_{\max }$ were calculated by using a stepwise backward elimination method at $\alpha=0.1$ while $\alpha=0.3$ was used for the $\rho_{\text {CFRP }}$ Pareto chart.

When looking at the Pareto charts for the four observed quality parameters, $\mathrm{E}_{\mathrm{f}}, \tau, \mathrm{z}_{\max }$ and $\rho_{\mathrm{CFRP}}$ which are shown in Figs. 11, 14, 16 and 18, one can see that there are only two parameters and one interaction between two parameters affecting the quality of the hybrid. The processing parameters are coded with the symbols A (mould temperature), B (resin temperature), $\mathrm{C}$ (mass flow change) and D (maximum injection pressure), as stated in Table 1.

The flexural modulus is mainly affected by the change in mass flow, the mould temperature and the interaction between the mould temperature and the resin temperature. The mass flow change is directly affecting the speed of the flow front. It has been shown that there is an optimum of flow front speed which is minimizing the void formation

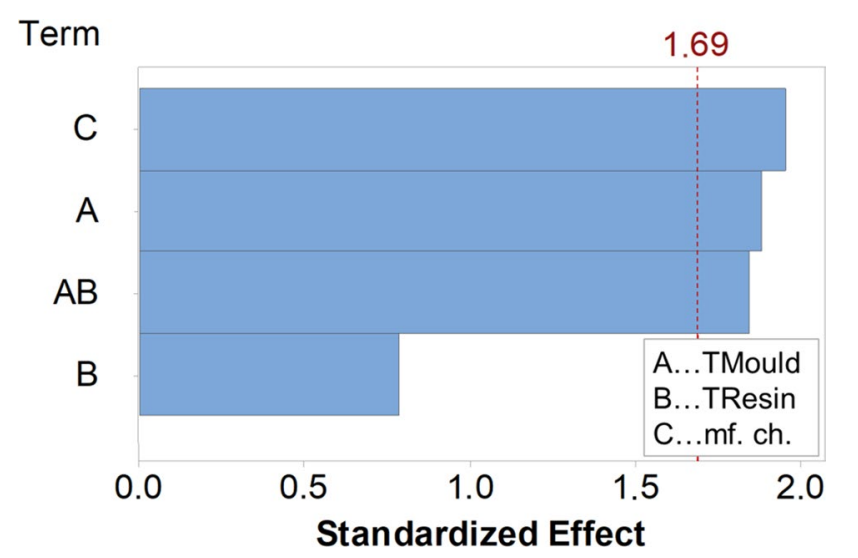

Fig. 11 Pareto chart for the flexural modulus $\mathrm{E}_{\mathrm{f}}$ whit $\alpha=0.1$ in the composite structure [19-21]. Furthermore it is well known that the amount of voids is indirect proportional to mechanical properties of composites [29-31]. According to Fig. 12, one can expect that a low flow front velocity is advantageous in this case. The mould temperature is also showing an influence on the flexural modulus. This can be explained by the higher reachable curing degree and the higher glass transition temperature of the epoxy resin system at a higher curing temperature while using the same curing time. Furthermore, there is an interaction of the mould temperature and the resin temperature. Figure 13 shows the interaction plot. The flexural modulus is rising with the higher mould temperature, but much more if the resin temperature is at the high level. This might be linked to the properties of the resin system. The viscosity of the resin system is decreased by increasing its temperature and when injecting the resin system into the fiber fabric it is getting heated up. While the heating effect is insufficient for the resin system with $65^{\circ} \mathrm{C}$, a better viscosity value is reached by the resin system with $75{ }^{\circ} \mathrm{C}$. This can reduce the void content due to different wetting behavior.

None of the tested processing parameters is affecting the apparent ILSS. The Pareto chart displayed in Fig. 14 was

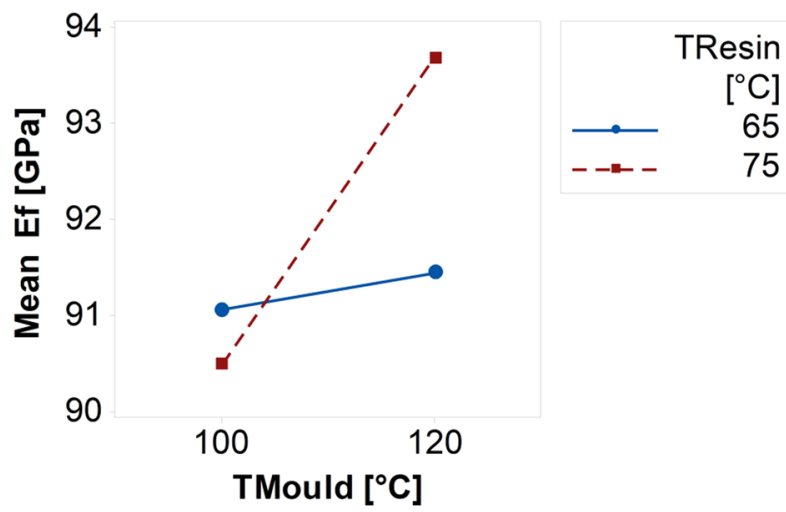

Fig. 13 Interaction plot for the mould temperature and resin temperature affecting the bending modulus $\mathrm{E}_{\mathrm{f}}$
Fig. 12 Main effects plot for the flexural modulus $\mathrm{E}_{\mathrm{f}}$ with a $90 \%$ confidence interval

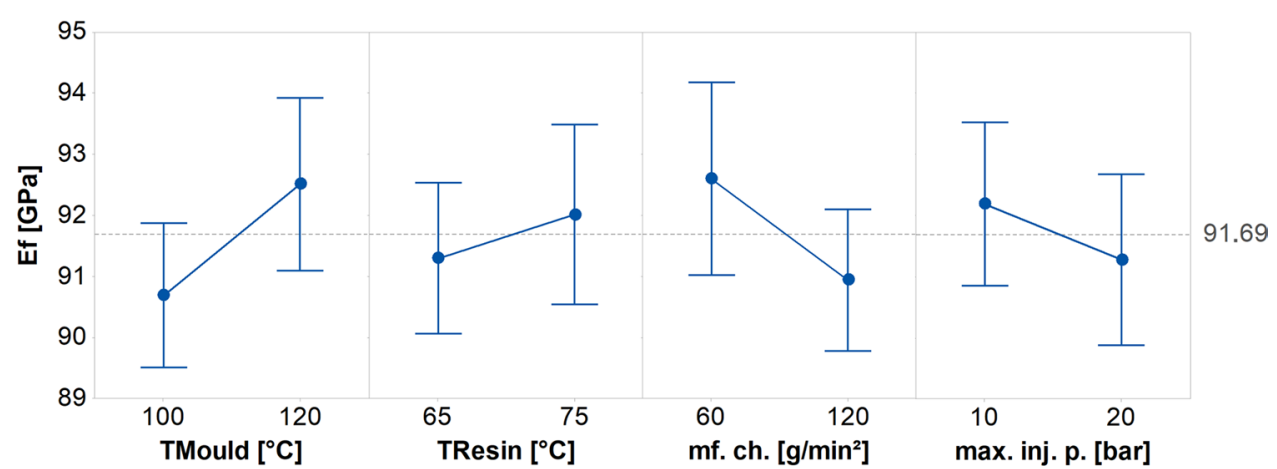




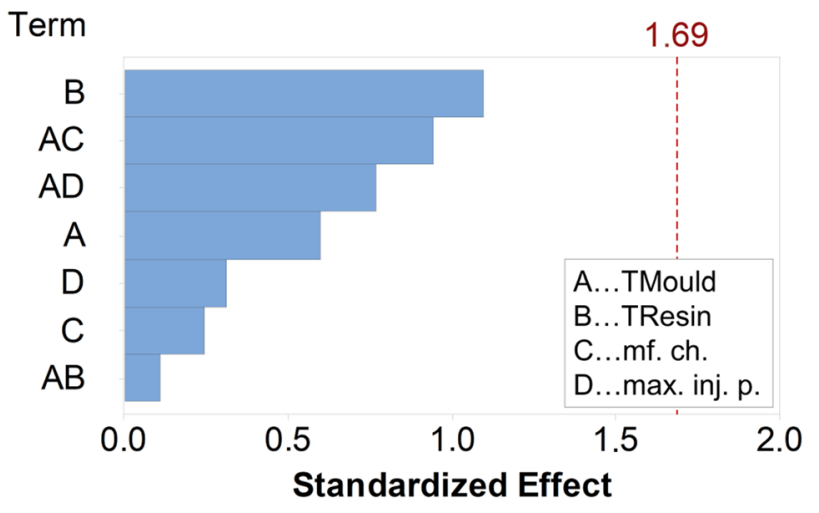

Fig. 14 Pareto chart for the apparent ILSS $\tau$ whit $\alpha=0.1$

created without using the elimination technique otherwise all parameters of the model would be eliminated. There are two ways to describe the absence of a significant influence on the apparent ILSS by the processing parameters. On the one hand, this can be linked to the high statistical uncertainty associated with the results shown in Fig. 8. The uncertainty might not only be linked to the testing method itself but also to damage induced while manufacturing the test specimen [32, 33]. This noise can also be seen in the main effect plot for the apparent ILSS in Fig. 15. On the other hand, it might simply be explained that there is no effect on the bonding of the metal towards the CFRP by the chosen processing parameters in their observation range.

The maximum deflection of the produced part is strongly affected by the mould temperature. This can clearly be seen at the Pareto chart shown in Fig. 16. It can be easily described by the different thermal expansion coefficients of the metal and the CFRP [16]. The coefficient was measured to be $10.0 \mathrm{E}-61 / \mathrm{K}$ for the metal while the in-plane thermal expansion coefficient of the CFRP is $3.5 \mathrm{E}-61 / \mathrm{K}$, respectively [34]. This discrepancy leads to the buckling of the steel CFRP hybrid causing the deflection which was predicted by finite element simulation previously [35]. The second significant effect is the change in mass flow. As explained above, this is linked to the flow

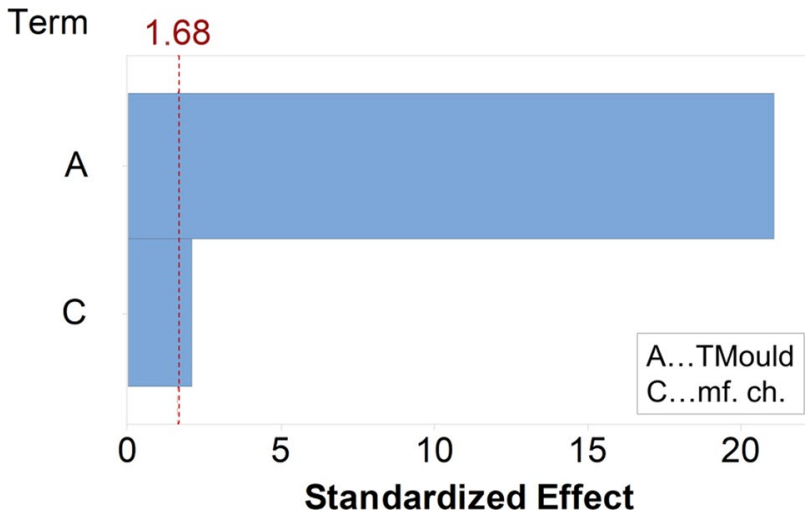

Fig. 16 Pareto chart for the maximum plat deflection $\mathrm{z}_{\max }$ whit $\alpha=0.1$

front speed and the void formation. A higher amount of voids in the composite structure might also change the thermal expansion coefficient. Nevertheless, as shown above the mass flow change has a significant influence on the flexural modulus of the composite which is shifting the elastic centre. Due to the mechanical properties of the used steel and CFRP the elastic centre is already shifted towards the steel component [36]. If the modulus of the CFRP is even more reduced the steel is getting more dominant and this will lead to a smaller deflection of the whole plate. The directions of the effects are displayed in Fig. 17 which is showing the main effect plot for the maximum deflection.

The void content is inverse proportional to the density of the CFRP and as Fig. 18 shows mainly affected by the interaction of the mould temperature and resin temperature. The orange stripe-dotted line at a standardized effect of 1.05 is indicating the border of $70 \%$ probability that the CFRP density is affected by the parameter. The mould temperature and the mass flow change are exceeding this threshold. This confirms the hypothesis stated above why the flexural modulus and the deflection is affected by these parameters. Due to the density measurement method and other parameters which are affecting the density, there is no higher probability reachable for the effect of these processing parameters.
Fig. 15 Main effects plot for the apparent ILSS $\tau$ with a $90 \%$ confidence interval

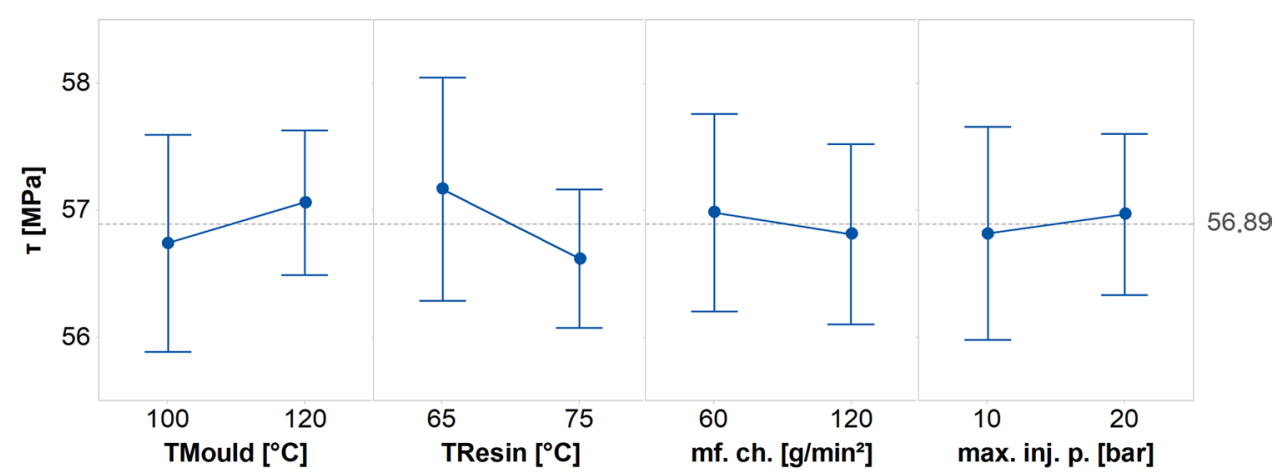


Fig. 17 Main effects plot for the maximum plate deflection with a $90 \%$ confidence interval

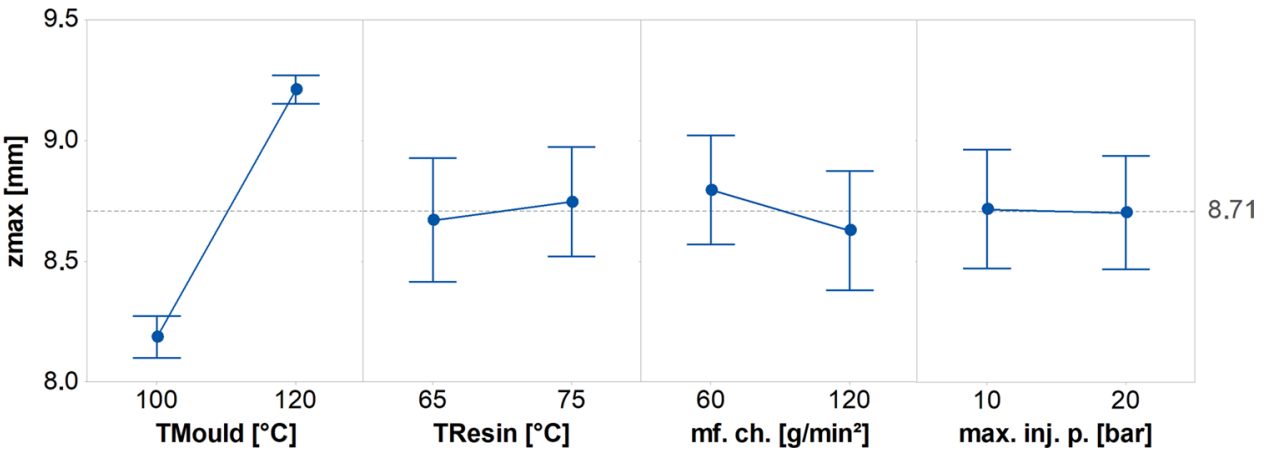

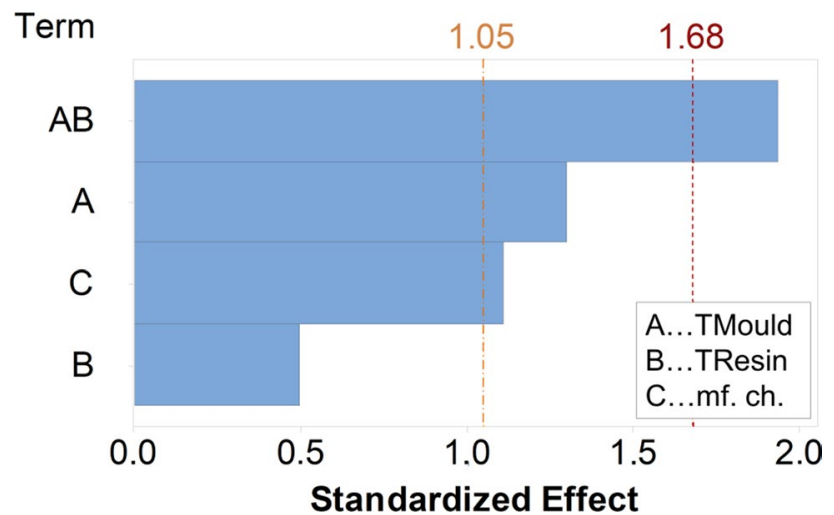

Fig. 18 Pareto chart for the CFRP density $\rho_{\text {CFRP }}$ whit $\alpha=0.1$ (red striped line at 1.68) and $\alpha=0.3$ (orange stripe-pointed line at 1.05)

Nevertheless, these effects can also be seen in Fig. 19, the main effect plot, and Fig. 20, the interaction plot for the CFRP density.

\section{Summary and conclusion}

This work shows the influence of processing parameters of the OSH-RTM process on the part quality. The flexural modulus $\mathrm{E}_{\mathrm{f}}$, the apparent ILSS $\tau$, the maximum deflection $\mathrm{z}_{\max }$ and the CFRP density $\rho_{\mathrm{CFRP}}$ of a hybrid plate made out

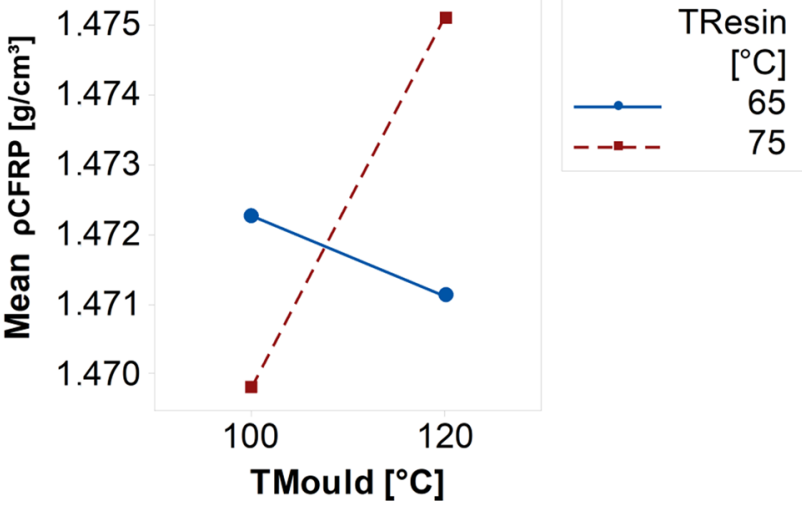

Fig. 20 Interaction plot for the mould temperature and resin temperature affecting the CFRP density $\rho_{\text {CFRP }}$

of steel and CFRP were specified as quality parameters. As changeable processing parameters, the mould temperature, resin temperature, change in mass flow and maximum injection pressure were defined and varied at two levels. It was shown that $E_{f}$ is affected by the change in mass flow, the mould temperature and an interaction between the mould and resin temperature, which can be linked to void formation on the one hand and a change of curing degree on the other hand. The results of the short beam three-point bending ILSS test were not able to reveal an effect of the processing parameters onto the interface strength of the hybrid
Fig. 19 Main effects plot for the CFRP density with a $90 \%$ confidence interval

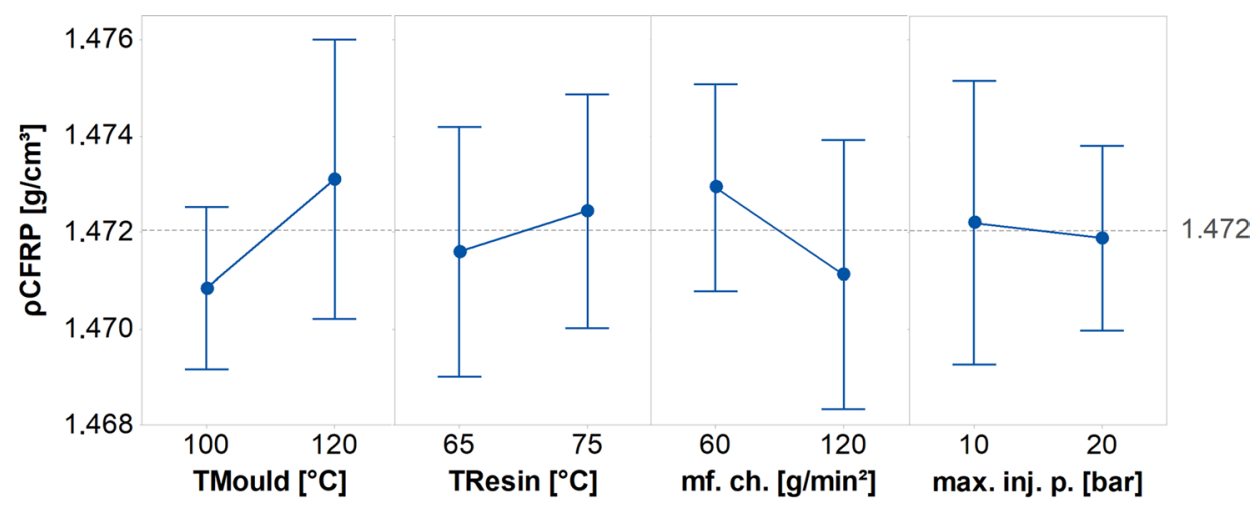


material. Nevertheless, there is a highly significant impact of the mould temperature on the maximum deflection of the steel CFRP hybrid plate, which is mainly driven by a difference in the thermal expansion coefficients of steel and CFRP. This effect is accompanied by a much smaller impact of the mass flow change on the maximum deflection, which is linked to the change of the flexural modulus shifting the elastic center further into the steel component. Measurement of CFRP density revealed that it is mainly influenced by the interaction of the mould and resin temperature. This interaction is leading to an advantageous behavior of the matrix system which results in higher density and therefore lower void content. To achieve an optimized part with a high flexural modulus and a low deflection a compromise has to be found. Therefore, a low mould temperature and an optimized mass flow change should be used.

Acknowledgements Open access funding provided by Montanuniversity Leoben. The work presented in this paper has been elaborated within the context of project "HybridRTM", financed through the Austrian Ministry for Transport, Innovation and Technology in the frame of the program "Produktion der Zukunft", administered by the Austrian Research Promotion Agency, which is greatly acknowledged.

Open Access This article is distributed under the terms of the Creative Commons Attribution 4.0 International License (http://creativeco mmons.org/licenses/by/4.0/), which permits unrestricted use, distribution, and reproduction in any medium, provided you give appropriate credit to the original author(s) and the source, provide a link to the Creative Commons license, and indicate if changes were made.

\section{References}

1. Ashby MF (2005) Hybrids to fill holes in material property space. Phil Mag 85(26-27):3235-3257. https://doi.org/10.1080/14786 430500079892

2. Girardy H (1992) Resin transfer molding: an answer to the problem of the industrialization of composites. Society of manufacturing engineers (ed) technical papers, Dearborn, pp 1-10

3. Holmberg JA, Berglund LA (1997) Manufacturing and performance of RTM U-beams. Compos Part A Appl Sci Manuf 28(6):513-521. https://doi.org/10.1016/S1359-835X(97)00001-8

4. Owen MJ, Middleton V, Hutcheon KF et al. (1988) Resin transfer moulding (RTM) for volume car production. In: Conference proceedings of the 16th reinforced plastics congress blackpool, pp 127-130

5. Lyu M-Y, Choi TG (2015) Research trends in polymer materials for use in lightweight vehicles. Int J Precis Eng Manuf 16(1):213220. https://doi.org/10.1007/s12541-015-0029-x

6. Bobbert M, Augethaler F, Wang Z et al (2016) Novel process approach for in-situ insertion of functional elements in RTMapplications. JMSR 6(1):15. https://doi.org/10.5539/jmsr.v6n1p 15

7. Nixon-Pearson OJ, Hallett SR, Withers PJ et al (2013) Damage development in open-hole composite specimens in fatigue. Part 1: experimental investigation. Compos Struct 106:882-889. https ://doi.org/10.1016/j.compstruct.2013.05.033
8. Araújo HAM, Machado JJM, Marques EAS et al (2017) Dynamic behaviour of composite adhesive joints for the automotive industry. Compos Struct 171:549-561. https://doi.org/10.1016/j.comps truct.2017.03.071

9. Caccese V, Kabche J-P, Berube KA (2007) Analysis of a hybrid composite/metal bolted connection subjected to flexural loading. Compos Struct 81(3):450-462. https://doi.org/10.1016/j.comps truct.2006.09.009

10. Melogranaa JD, Grenestedt JL, Maroun WJ (2003) Adhesive tongue-and-groove joints between thin carbon fiber laminates and steel. Compos Part A Appl Sci Manuf 34(2):119-124. https://doi. org/10.1016/S1359-835X(03)00005-8

11. Tang S, Lu N, Myung S-W et al (2006) Enhancement of adhesion strength between two AISI $316 \mathrm{~L}$ stainless steel plates through atmospheric pressure plasma treatment. Surf Coat Technol 200(18-19):5220-5228. https://doi.org/10.1016/j.surfc oat.2005.06.020

12. Wang Z, Bobbert M, Dammann C et al (2016) Influences of interface and surface pretreatment on the mechanical properties of metal-CFRP hybrid structures manufactured by resin transfer moulding. IJAUTOC 2(3/4):272. https://doi.org/10.1504/IJAUT OC.2016.10005305

13. Wang Z, Lauter C, Sanitther B et al (2016) Manufacturing and investigation of steel-CFRP hybrid pillar structures for automotive applications by intrinsic resin transfer moulding technology. IJAUTOC 2(3/4):229. https://doi.org/10.1504/IJAUTOC.2016.084322

14. Fauster E, Hergan P, Schledjewski R (2016) HybridRTM-quality controlled manufacturing of hybrid material composites through resin transfer moulding. In: Proceedings of euro hybrid materials \& structures 2016 Kaiserslautern

15. Beter J (2017) Design of Experiments Versuche an Hybridplatten-Betrachtung der Phänomene des RTM-Prozesses. Masterarbeit, Montanuniversität Leoben

16. Yoshitake I, Tsuda H, Itose J et al (2014) Effect of discrepancy in thermal expansion coefficients of CFRP and steel under cold temperature. Constr Build Mater 59:17-24. https://doi.org/10.1016/j. conbuildmat.2014.02.051

17. Hergan P, Beter J, Stelzer S et al. (2017) Influence of processing temperatures on the deflection of hybrid-metal-carbon composites made by resin transfer moulding. In: Proceedings of the $21 \mathrm{st}$ international conference on composite materials Xi'An

18. Dong C, Kang L (2012) Deformation and stress of a compositemetal assembly. Int J Adv Manuf Technol 61(9-12):1035-1042. https://doi.org/10.1007/s00170-011-3757-9

19. Ruiz E, Achim V, Soukane S et al (2006) Optimization of injection flow rate to minimize micro/macro-voids formation in resin transfer molded composites. Compos Sci Technol 66(3-4):475-486. https://doi.org/10.1016/j.compscitech.2005.06.013

20. Kurematsu K, Koishi M (1985) Kinetic studies on void formation during liquid epoxy resin impregnation through polyester nonwoven fabric. Colloid Polym Sci 263(6):454-461. https://doi. org/10.1007/BF01458335

21. Jinlian H, Yi L, Xueming S (2004) Study on void formation in multi-layer woven fabrics. Special Issue Flow Process Compos Mater 35(5):595-603. https://doi.org/10.1016/j.composites a.2003.11.007

22. Horodek P, Eseev MK, Kobets AG (2015) Studies of stainless steel exposed to sandblasting. Nukleonika 60(4):101. https://doi. org/10.1515/nuka-2015-0129

23. Kim YJ, Bumadian I (2016) Electrochemical reactions for steel beams strengthened with CFRP sheets. Eng Struct 125:471-480. https://doi.org/10.1016/j.engstruct.2016.07.029

24. Zhang C, Zheng D-J, Song G-L (2017) Galvanic effect between galvanized steel and carbon fiber reinforced polymers. Acta Metall Sin (Engl Lett) 30(4):342-351. https://doi.org/10.1007/s4019 5-017-0539-x 
25. Grubbs FE (1950) Sample criteria for testing outlying observations. Ann Math Stat 21(1):27-58. https://doi.org/10.1214/ aoms/1177729885

26. Dixon WJ (1953) Processing data for outliers. Biometrics 9(1):74. https://doi.org/10.2307/3001634

27. Minitab Inc (2017) Effects plots for analyze factorial design. https ://support.minitab.com/en-us/minitab/18/help-and-how-to/model ing-statistics/doe/how-to/factorial/analyze-factorial-design/inter pret-the-results/all-statistics-and-graphs/effects-plots/. Accessed 11 Nov 2017

28. Minitab Inc (2017) Methods and formulas for the effects plots in analyze factorial design: pareto chart. https://support.minit ab.com/en-us/minitab/18/help-and-how-to/modeling-statistics/ doe/how-to/factorial/analyze-factorial-design/methods-and-formu las/effects-plots/. Accessed 31 Oct 2017

29. Guo Z-S, Liu L, Zhang B-M et al (2009) Critical void content for thermoset composite laminates. JCompos Mater 43(17):17751790. https://doi.org/10.1177/0021998306065289

30. Carraro PA, Maragoni L, Quaresimin M (2015) Influence of manufacturing induced defects on damage initiation and propagation in carbon/epoxy NCF laminates. Adv Manuf Polym Compos Sci 1(1):44-53. https://doi.org/10.1179/2055035914Y.0000000004
31. Endruweit A, Zeng X, Long AC (2015) Multiscale modeling of combined deterministic and stochastic fabric non-uniformity for realistic resin injection simulation. Adv Manuf Polym Compos Sci 1(1):3-15. https://doi.org/10.1179/2055035914Y.0000000002

32. Turner J, Scaife RJ, El-Dessouky HM (2015) Effect of machining coolant on integrity of CFRP composites. Adv Manuf Polym Compos Sci 1(1):54-60. https://doi.org/10.1179/2055035914 Y.0000000008

33. Islam F, Ramkumar J, Milani AS (2016) A simplified damage prediction framework for milling of unidirectional carbon fiberreinforced plastics. Adv Manuf Polym Compos Sci 1(4):175-184. https://doi.org/10.1080/20550340.2015.1117747

34. Brandstetter D (2016) Charakterisierung eines im RTM-Prozess hergestellten CFK-Metall-Leichtbauwerkstoffes, Montanuniversität Leoben

35. Scheiblhofer S (2017) Deformation prediction of RTM produced hybrid metal-carbon composites. In: NAFEMS World Congress 2017, Stockholm

36. Hetnarski RB, Eslami MR, Gladwell GML (eds) (2009) Thermal stresses-advanced theory and applications. Solid mechanics and its applications, vol 158, Springer, Dordrecht 